\title{
Root-Colonizing Endophytic Fungi of the Dominant Grass Stipa krylovii From a Mongolian Steppe Grassland
}

\author{
Dániel G. Knapp ${ }^{1 * t}$, Ildikó Imrefi't, Enkhtuul Boldpurev ${ }^{1}$, Sándor Csíkos ${ }^{1}$, \\ Galiya Akhmetova ${ }^{1}$, Péter János Berek-Nagy ${ }^{1}$, Burenjargal Otgonsuren ${ }^{2}$ and \\ Gábor M. Kovács ${ }^{1 *}$
}

' Department of Plant Anatomy, Institute of Biology, Eötvös Loránd University, Budapest, Hungary, ${ }^{2}$ Department of Ecology, Mongolian University of Life Sciences, Ulaanbaatar, Mongolia

\section{OPEN ACCESS}

Edited by:

Fu-Cheng Lin,

Zhejiang University, China

Reviewed by:

Chulong Zhang,

Zhejiang University, China

Iñigo Zabalgogeazcoa,

Institute of Natural Resources and Agrobiology of Salamanca

(IRNASA), Spain

*Correspondence:

Dániel G. Knapp

danielgknapp@ttk.elte.hu

Gábor M. Kovács

gmkovacs@caesar.elte.hu

tThese authors have contributed equally to this work

Specialty section:

This article was submitted to Fungi and Their Interactions,

a section of the journal

Frontiers in Microbiology

Received: 08 July 2019 Accepted: 23 October 2019 Published: 12 November 2019

Citation:

Knapp DG, Imrefi I, Boldpurev E,

Csíkos S, Akhmetova G, Berek-Nagy PJ, Otgonsuren $B$ and Kovács GM (2019) Root-Colonizing

Endophytic Fungi of the Dominant Grass Stipa krylovii From a Mongolian

Steppe Grassland.

Front. Microbiol. 10:2565. doi: 10.3389/fmicb.2019.02565
In several terrestrial ecosystems such as grasslands, plants live together with various root-colonizing dark septate endophytes (DSEs), fungi that are relatively frequent colonizers of healthy belowground tissues of plants in these environments. They are important members of the plant microbiota and may have various effects on plant survival under different stress conditions; however, their general functions in relation to plants and the greater ecosystem remain elusive. Although an increasing number of studies has been published focusing on DSEs in Asian grasslands, our knowledge is limited. Especially in Mongolia, where the steppe region represents a significant area, information is not available on these root colonizers. In this study, we aimed to characterize DSEs of a common dominant gramineous plant species, Stipa krylovii in a semiarid grassland of Mongolia. Root samples were collected in a natural steppe and were processed for isolation of fungal endophytes. For molecular identification of the isolates, the internal transcribed spacer (ITS) region of the nrDNA was obtained for all the isolates investigated; furthermore, the partial translation elongation factor $1-\alpha$ (TEF) gene and large subunit (LSU) and small subunit (SSU) of rDNA were also amplified and sequenced in case of representative isolates. In vitro tests were used to examine the rough symbiotic nature of the fungi, and root colonization was visualized. A majority of the 135 isolates examined in detail was found to belong to several orders of Ascomycota (110 isolates) and some to Basidiomycota (25 isolates). A significant number of the isolates represented presumably novel taxa, and dominant similarities of the lineages have been found with relatively frequent and known grass root endophytes of semiarid areas in other geographic regions. These endophytes included Periconia macrospinosa, Microdochium bolley, and Darksidea, the genus of which comprised one fourth of the isolates. We found numerous lineages, which have been detected not only from Asian steppe ecosystems, but also from prairies in North America and sandy grasslands in Europe. Therefore, our results strengthen the hypothesized worldwide presence of a common and dominant core group of a DSE community in arid and semiarid grasslands.

Keywords: Asia, diversity, phylogeny, Pleosporales, root-associated fungi 


\section{INTRODUCTION}

In grasslands, as in other terrestrial ecosystems, plants form symbioses with diverse fungal endophytes, which colonize the plant tissues without causing obvious symptoms during at least one part of their life cycle (Wilson, 1995; Saikkonen et al., 1998). Endophytic fungi are also present in healthy belowground tissues (Vandenkoornhuyse et al., 2002; Rodriguez et al., 2009), albeit knowledge of their general occurrence and their potential functions is lacking compared with what we know of mycorrhizal fungi. Apart from behaving as commensalistic symbionts, fungal endophytes also act as latent pathogens, latent saprotrophs, and mutualistic partners (Porras-Alfaro and Bayman, 2011; Yakti et al., 2019a). These form a group of root-colonizing endophytic fungi, generally called dark septate endophytes (DSEs), which refer to their mainly melanized and septate hyphae. These fungi dominate several biomes and climatic regions, including grasslands, yet their functions in relation to plants and the greater ecosystem are still elusive (Mandyam and Jumpponen, 2005; Sieber and Grünig, 2013). They might have an important role as saprobes because comparative genomics, for example, of DSE fungi revealed an expansion of carbohydrate active enzyme families (Knapp et al., 2018). Therefore, degrading complex carbohydrates such as dead plant tissues could be a key characteristic of the lifestyle of DSE fungi (Knapp et al., 2018). The study of enzymes and carbon source use of DSEs also revealed a diverse enzymatic capacity showing complementary distribution within DSEs of grass and nongrass hosts (Knapp and Kovács, 2016). The effect of DSE fungi on the performance of their host plants varies (Newsham, 2011; Mayerhofer et al., 2013; Mandyam and Jumpponen, 2015); in addition to influencing nutrient uptake (Yakti et al., 2019a,b), they could increase the drought stress resistance as well (Li et al., 2018).

In arid, semiarid, and temperate grasslands of North America and Europe, DSE communities and non-mycorrhizal rootassociated fungi have been thoroughly studied, and these fungi are relatively frequent in these ecosystems (e.g., Kovács and Szigetvári, 2002; Mandyam and Jumpponen, 2005; Porras-Alfaro et al., 2008; Sánchez-Márquez et al., 2008; Knapp et al., 2012). The results suggest that there are core members of those communities common to disparate regions, not only in North America (Khidir et al., 2010) but also worldwide (Knapp et al., 2012). In the past few years, an increasing number of studies has been published focusing on fungal root endophytes of Asian grasslands, mainly in China (e.g., Su et al., 2010; Li et al., 2015, 2018; Xie et al., 2017). However, information about DSEs from other sites and countries in the eastern part of the Steppe belt, including Mongolia, where the steppe represents a significant part of the area (Ulziikhutag, 1989), is not available.

In Mongolia, in addition to alpine tundra, mountain taiga and deserts, three types of grass-dominated ecosystems can be found: mountain forest-steppe, steppe, and desert steppe. These are formed because of climate shifts from humid to arid conditions, and grazing may also affect the water cycle of the grassland ecosystem (Ulziikhutag, 1989). Areas of Mongolia are classified as arid and semi-arid regions (Begzsuren et al., 2004) and about $70-80 \%$ of the total land area in Mongolia is made up of grasslands comprising the three steppe types (Ulziikhutag, 1989; Liu et al., 2013), which are freely grazed by livestock year round (FernandezGimenez and Allen-Diaz, 1999). Similar to the grassland ecosystems in China, a couple of grass species, including Stipa krylovii and Stipa grandis, dominate the landscape at certain areas in Mongolia (Zhao et al., 2006; Kang et al., 2007; Tuvshintogtokh, 2014). Other dominant gramineous species of the steppes are Cleistogenes squarrosa, Leymus chinensis, Agropyron cristatum, Caragana microphylla, and Caragana stenophylla (Tuvshintogtokh, 2014).

Stipa krylovii is an important perennial tussock grass in the Mongolian steppe ecosystem and its communities represent a major grassland type in the moderate temperate zone of Central Asia (Zhao et al., 2006). This grass is a primary forage in some Mongolian steppe areas for grazing mammals (e.g., Retzer, 2007) along with A. cristatum, which is widely used in the restoration of the Mongolian prairie (Otgonsuren and Lee, 2010). S. krylovii has been widely studied in several works owing to its outcrossing mating system, and ecological and economic importance (e.g., Yuan et al., 2005; Wang et al., 2006; Zhan et al., 2007; Li et al., 2014). Although studies focusing on this grass were started in the 1950s, with documentation of its distribution, growth, physiology, life history, and the response to grazing (Zhao et al., 2006), its root-colonizing endophytic communities remained unknown. Besides understanding the genetic diversity of population, onto which several works addressed questions (e.g., Wang et al., 2006; Zhao et al., 2006), studies on the relationship of this grass species with its microbiota, including fungal root endophytes, should be highly important owing to the hypothesized major impact of DSEs on their host plants in arid conditions (e.g., Li et al., 2018).

Card et al. (2014), in their study, investigated Epichloë/Neotyphodium endophytes colonizing shoots of grasses in several countries, including Mongolia; however, to date, we are not aware of any studies focusing on root endophytes of Mongolian grasslands. In the present study, we introduce the first information on DSEs of a dominant and widespread grass species from Mongolia. Similar to China (Zhao et al., 2005), desertification is an important issue in Mongolia, where $90 \%$ of the land is fragile dry land under increasing threat from this kind of land degradation (Chen et al., 2007). Therefore, information on the DSE community, which can affect plant survival and production, and its putative similarity to other grasslands, like those in European and North American prairies, may help applied approaches in farming or conservation.

In this study, we examined the root-colonizing fungal endophytes of a common and dominant gramineous plant species of semiarid grasslands in Mongolia. Our aims were to isolate fungal endophytes from the roots of S. krylovii from a natural Mongolian Steppe, carry out their molecular phylogenetic identification and to test their endophytic lifestyle in an artificial in vitro resynthesis experiment. 


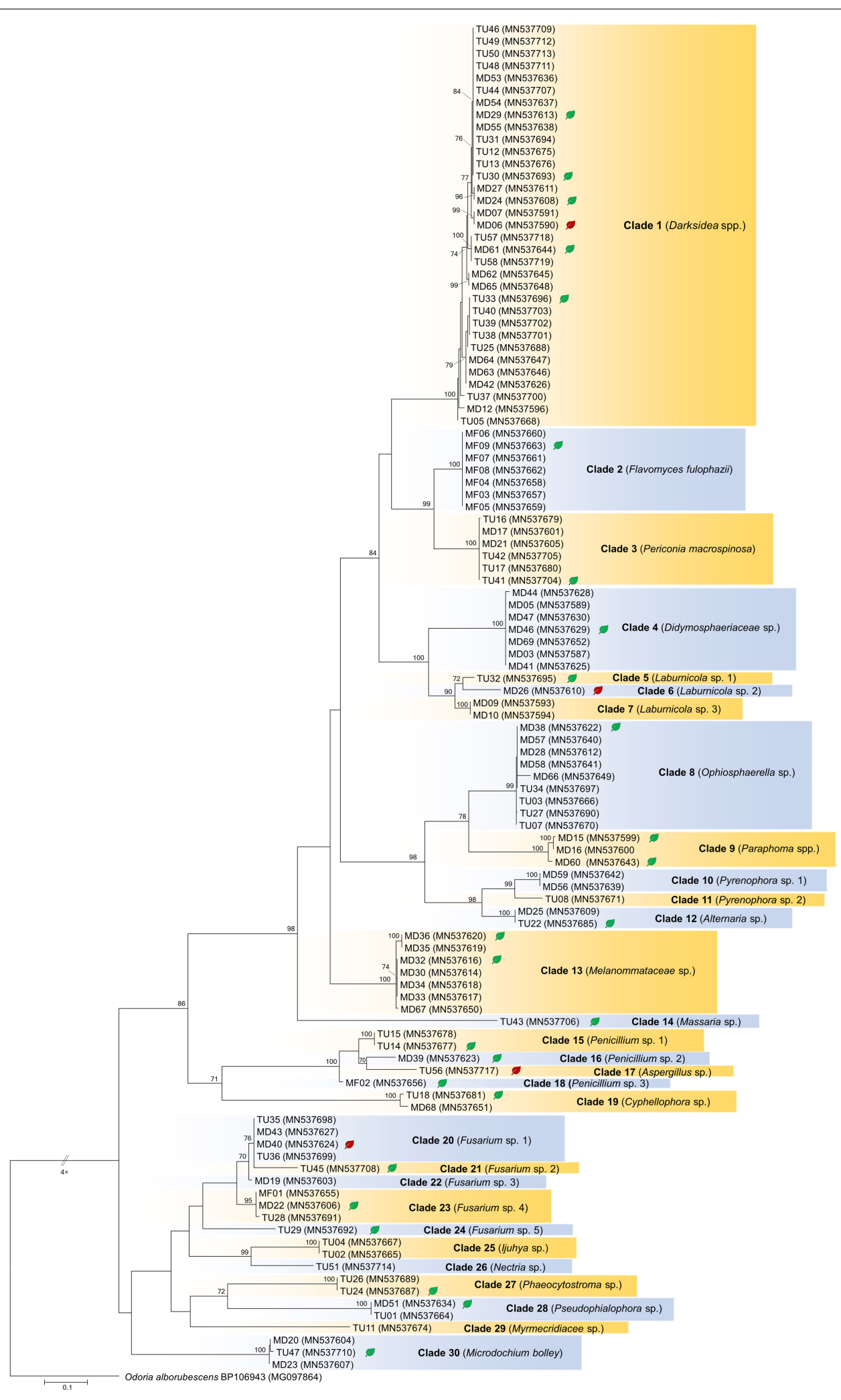

FIGURE 1 | Maximum likelihood (RAxML) phylogenetic tree of ITS sequences of isolates belonging to Ascomycota. ML bootstrap support values ( $\geq 70$ ) are shown at the branches. The basidiomycete Odoria alborubescens BP106943 served as outgroup. After the isolate names, GenBank accession numbers are shown in brackets. Leaves indicate the representative isolates tested by inoculation of leek; isolates with negative effect are labeled with red, and green leaves indicate no visible symptoms caused by the isolate. The scale bar indicates 0.05 expected changes per site per branch. 


\section{MATERIALS AND METHODS}

\section{Sampling}

The root samples were taken from S. krylovii from a grassland ecosystem near Kherlenbayan-Ulaan (KBU, Mongolia), where this is the dominant gramineous species. Samples were collected in a natural steppe zone located in the Nalaikh district, $\sim 38.6 \mathrm{~km}$ from the capital city of Ulaanbaatar, Mongolia. The region has semiarid characteristics with warm summers (Bereneva, 1992), the mean annual precipitation is $235 \mathrm{~mm}$, and the mean temperature in January and July are $-22.5^{\circ} \mathrm{C}$ and $17^{\circ} \mathrm{C}$, respectively (averages for 2009-2018 at Nalaikh; National Agency for Meteorology and Environmental Monitoring, Mongolia). Sampling of S. krylovii roots was carried out on the 8th of October in 2016. The elevation of the collection site (N 47.729611 , E 107.225104) is $1400-1450 \mathrm{~m}$. Root samples were collected from 20 tussocks of S. krylovii with $\sim 1 \mathrm{~m}$ distance from one another along a transect. A bunch of root pieces and a small amount of moist soil were collected, put into plastic bags and kept in a cool condition. Samples, containing approximately 5-50 pieces of root per tussock, were cleaned from soil, folded into moist paper towels, and the roots were processed within 8 days.

\section{Isolation of Root Endophytes}

Roots of S. krylovii were surface sterilized according to Knapp et al. (2012), and each sample was sliced into 2- to 3-cm segments and soaked in $30 \% \mathrm{H}_{2} \mathrm{O}_{2}$ for $2 \mathrm{~min}$, then in $70 \%$ alcohol for $1 \mathrm{~min}$, and washed in sterile tap water two times for 2-3 min each time. After surface sterilization, each root segment was cut into four pieces by a scalper and placed onto modified Melin-Norkrans (MMN) media (Marx, 1969). After 5-7 days, we observed the

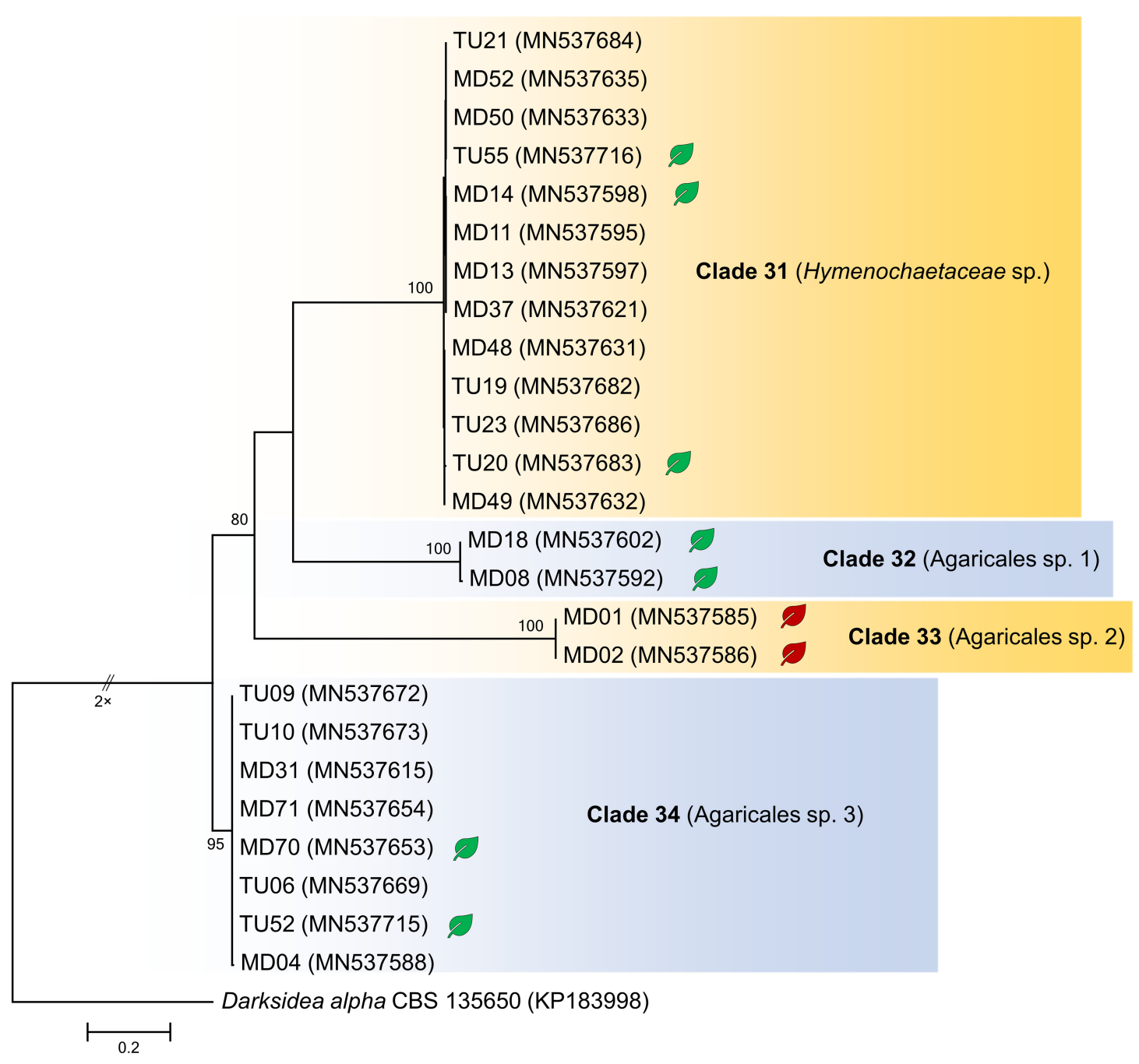

FIGURE 2 | Maximum likelihood (RAxML) phylogenetic tree of ITS sequences of isolates belonging to Basidiomycota. ML bootstrap support values ( $\geq 70$ ) are shown at the branches. The ascomycete Darksidea alpha CBS 135650 served as outgroup. After the isolate names, GenBank accession numbers are shown in brackets. Leaves indicate the representative isolates tested by inoculation of leek; isolates with negative effect are labeled with red, and green leaves indicate no visible symptoms caused by the isolate. The scale bar indicates 0.05 expected changes per site per branch. 
growing hyphae from the roots and the pure mycelia were transferred to new agar plates.

\section{In vitro Tests and Microscopy}

In vitro tests were performed with representatives of each clade obtained by the analyses of internal transcribed spacer (ITS) sequences of the fungal isolates (Figures 1, 2) using leek (Allium porrum), a generally used host plant in DSE resynthesis experiments (see Mandyam and Jumpponen, 2008; Knapp et al., 2012) to test the basic symbiotic nature of the fungi. Five replicates for each fungal isolate and five control plants were incubated in each series according to Knapp et al. (2012). The fungus and isolates of its clade were considered a root endophyte if it colonized the roots without symptoms.

Root samples from the field and in vitro experiments were studied microscopically. The cleared roots were stained using the fluorescence labeled lectin, WGA-AlexaFluor488 (Wheat Germ Agglutinin, Alexa Fluor 488 conjugate, Molecular Probes W11261, Thermo Fisher Scientific, Lithuania), a cell-wall-specific dye used for in planta visualization of fungal endophytes (e.g., Andrade-Linares et al., 2011). Root samples were examined using a light microscope with Nomarski (differential interference contrast, DIC) optics and a Nikon Eclipse 80i microscope equipped with a Spot 7.4 Slider camera (Diagnostic Instruments, Inc.), differential interference contrast (DIC), and a filter wheel with excitation and emission filters for visualization of Alexa Fluor 488 probe.

\section{DNA Extraction, Amplification, and Sequencing}

Genomic DNA was extracted from fungal mycelia using a modified cetyl trimethylammonium bromide (CTAB) method (Murray and Thompson, 1980; Kovács et al., 2001) or the NucleoSpin Plant II DNA Isolation Kit (MACHEREYNAGEL, Germany) following the manufacturer's instructions. The nuclear rDNA ITS1-5.8S-ITS2 (ITS) region of all isolates was amplified and sequenced using the primer pair ITS1F (Gardes and Bruns, 1993) and ITS4 (White et al., 1990). For representative strains of distinct lineages, the partial $28 \mathrm{~S}$ rDNA (LSU), partial 18S rDNA (SSU), and the partial translation elongation factor $1 \alpha$ (TEF) were amplified with the primers LR0R (Rehner and Samuels, 1994) and LR5 (Vilgalys and Hester, 1990), NS1 and NS4 (White et al., 1990), and EF1-983F and EF1-2218R (Rehner and Buckley, 2005), respectively. For polymerase chain reaction, DreamTaq polymerase (Thermo Fisher Scientific, Vilnius, Lithuania) was used, and sequencing of the amplicons was carried out with the amplification primers from LGC GmbH (Berlin, Germany). The sequences were compiled from electropherograms using the PREGAP4 and GAP4 tools of the Staden software package (Staden et al., 2000) and deposited in GenBank (ITS: MN537585-MN537719; LSU: MN515229-MN515287; SSU: MN515296-MN515302; TEF: MN535230-MN535285; see Supplementary Table S1). The sequences obtained were compared with sequences in public databases using BLASTn searches (Altschul et al., 1990).

\section{Phylogenetic Analyses}

Different data sets were prepared for phylogenetic analyses including sequences of the isolates collected from $S$. krylovii roots studied here and similar sequences obtained from public databases (Supplementary Table S2). Alignments of the sequences were assembled using the E-INS-i method in MAFFT 7 (Katoh and Standley, 2013) and were checked and edited with MEGA6 (Tamura et al., 2013) and deposited in TreeBASE (study S25135). For the data sets, multilocus phylogenetic Bayesian inference (BI) analyses were performed with MrBayes 3.1.2 (Ronquist and Huelsenbeck, 2003) using the GTR + G nucleotide substitution model. Four Markov chains were run for 10,000,000 generations and sampled every 1000 generations with a burnin value set at 6000 sampled trees. Maximum likelihood (ML) phylogenetic analyses were carried out with the raxmlGUI 1.3 (Silvestro and Michalak, 2012) implementation of RAxML (Stamatakis, 2014). The GTR + G nucleotide substitution model was used for the partitions with ML estimation of base frequencies, and a ML bootstrap analysis with 1000 replicates was used to test the support for the branches. The phylogenetic trees were visualized and edited using MEGA6 (Tamura et al., 2013).

\section{RESULTS}

During the isolation process, more than 1000 root sections were surface sterilized and laid onto media, and approximately 350 isolates were obtained from the $20 \mathrm{~S}$. krylovii tussocks that originated from a Mongolian grassland. In most cases, isolates collected from the same root of one S. krylovii tussock showed identical colony morphology. Because endophytes from the same root with similar colony morphology were considered to represent the same taxa, 135 isolates were finally used in the subsequent molecular identification and analysis. Isolates were obtained from all the tussocks sampled, and each of the field collected roots showed frequent colonization by DSE fungi.

The collected isolates belonged to the Dikarya group and represented diverse orders of Ascomycota, Pezizomycotina (110 isolates), Basidiomycota, and Agaricomycotina (25 isolates). Based on ITS sequences, the isolates represented 34 clades introduced here as clades 1-34, from which 30 comprised ascomycetous and 4 comprised basidiomycetous fungi (Figures 1, 2). The most numerous clade, possessing almost one fourth of the collected fungi, consists of 33 isolates (clade 1), followed by clade 31 and clade 8 with 13 and 9 isolates, respectively (Figures 1, 2). The majority of the isolates (125) belonged to non-singleton clades while 10 clades contained only one isolate.

For the in vitro colonization tests, 39 representative isolates of the 34 clades were chosen (Figures 1, 2). The healthy A. porrum plants had generally well-developed root systems and five to six leaves after 6 weeks. All the fungi used for inoculation colonized the roots extra- and intraradically, showing typical structures, such as microsclerotia, chlamydospores, or intracellular septate hyphae (Figure 3). Altogether, only six isolates, representing five groups [clades 6, 17, 20, 33 and the MD06 from clade 1 (Figures 1, 2)], showed negative effects on the hosts; the plants inoculated 

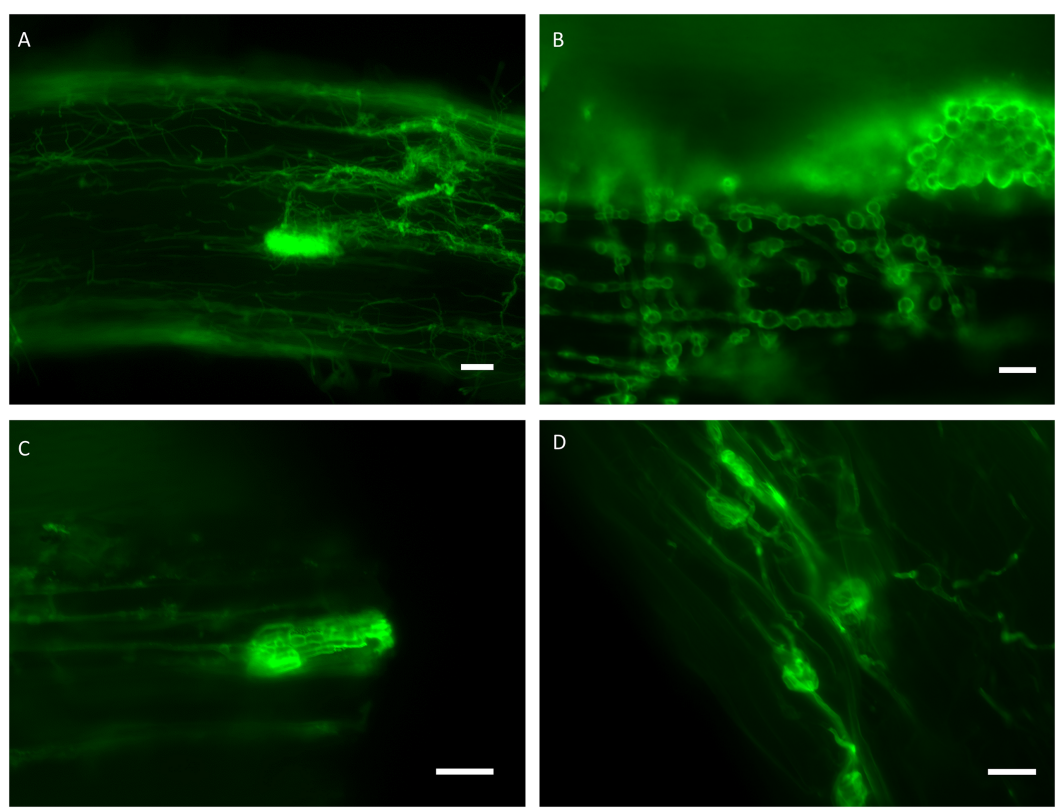

FIGURE 3 | Representative isolates of different clades colonizing the roots of leek visualized by WGA-Alexa Fluor ${ }^{\circledR} 488$. (A) Intra- and extraradical hyphae and a microsclerotia formed by the isolate MD39 (clade 16). (B) Moniliform hyphae and an extraradical compacted structure of the isolate MF09 (clade 2). (C) Intraradical hyphae and a microsclerotia formed by the isolate MF09 (clade 2). (D) Intraradical hyphae and chlamydospore-like structures of the isolate TU56 (clade 17) within the dead root. Bars: $20 \mu \mathrm{m}$ (B-D), $50 \mu \mathrm{m}$ (A).

with these isolates died within 2 weeks. In most cases, the leeks did not show considerable difference from the control plants.

The isolates showed diverse colony morphology, growing characteristics, color, and shape on agar plates. The colony of some isolates covered the whole $5-\mathrm{cm}$ Petri dish, and other colonies remained only $1.0-1.5 \mathrm{~cm}$ in diameter. The presence of visible/coloring exudates was not common, and sporulation was observed only in case of a few Aspergillus and Penicillium isolates. Some isolates stained the media (e.g., isolates of clades 1 and 2). Based on molecular phylogenetic identification, the majority of the clades could be identified at species or genus level, whereas others could be identified only at higher taxonomic levels (Supplementary Table S3). Pleosporales (Dothydeomycetes) was the most represented order with 81 isolates and 13 clades $(81 / 13)$, followed by Hymenochaetales (13/1) and Hypocreales (9/7). The blast analysis revealed similarities in the isolates with root endophytes from grasslands of other geographic regions; for instance, Periconia macrospinosa (clade 3), Microdochium bolley (clade 30), or the recently described genus, Darksidea (clade 1 ), from taxa that are relatively frequent and are known root endophytes of grasses of semiarid areas (Mandyam et al., 2010; Knapp et al., 2012, 2015; Jumpponen et al., 2017). Altogether, 20 lineages (clades 1, 2, 3, 4, 5, 9, 10, 11, 12, 13, 15, 19, 22, 25, $26,27,29,30,33$, and 34) comprising more than two thirds of the isolates gathered (95) showed unambiguous ITS sequence similarities (at least 99\%) with blast hits from different grassland ecosystems (Supplementary Table S3). Based on the blast analyses and the multilocus phylogenies, a significant number of the clades represents presumably novel taxa (Figures 4, 5, 6 and Supplementary Table S3).
Our isolates represented several families within Pleosporales (Figure 4). The largest group with the highest number of isolates was clade 1 representing Darksidea species within Lentitheciaceae. The isolates in clades 5-7 belong to the genus Laburnicola representing the Didymosphaeriaceae along with clade 4, a distant and novel lineage. Clades 2 and 3 represent Flavomyces fulophazii and P. macrospinosa in Periconiaceae, while Phaeosphaeriaceae and Pleosporaceae comprise clades 8 and 9 , and clades 10-12, respectively. The three isolates of clade 13 represent another novel taxon in Melanommataceae (Figure 4).

Phylogenetic analysis of our representative isolates and related sequences in Sordariomycetes revealed numerous novel lineages (Figure 5). Clades 20-24 comprised possibly different Fusarium species in Nectriaceae, and isolates of clades 25 and 26 represented the family Bionectriaceae. Low numbers of endophytic isolates in clades 27-29 represented Myrmecridiaceae, Diaporthaceae, and Magnaporthaceae, respectively. The three isolates representing clade 30 showed similarities with $M$. bolley and belonged to Microdochiaceae (Figure 5).

As mentioned above, clade 1 encompassed a large number of isolates and represented the diverse genus, Darksidea (Figure 6). The phylogenetic analysis based on the ITS, TEF, and LSU regions of the isolates showed that most of the isolates represented D. alpha and grouped together with the well-described strains, including the ex-type strain CBS 135650. In addition to the sensu stricto D. alpha group, MD06 and MD07 represent a closely related lineage similarly to MD61, TU57, and TU58, and the solely branching MD62. These lineages may belong to D. alpha or represent novel taxa (Figure 6). Eight isolates represented a diverse lineage as a sister group of the monotypic species D. zeta. 


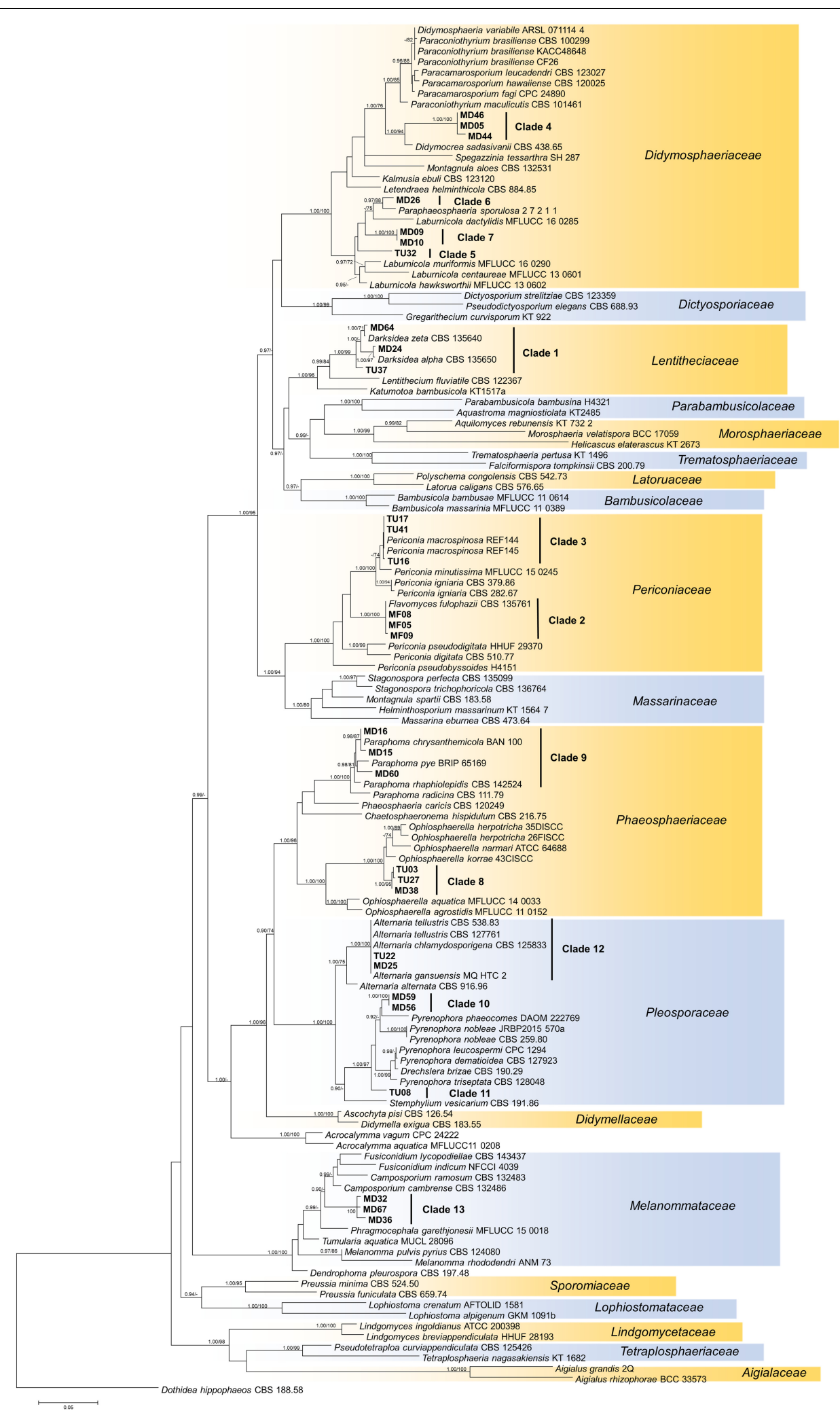

FIGURE 4 | Maximum likelihood (RAxML) phylogenetic tree of representative sequences from Pleosporales based on the analysis of three loci (LSU, ITS, and TEF). Bayesian posterior probabilities ( $\geq 90)$ are shown before slashes; ML bootstrap support values $(\geq 70)$ are shown after slashes. Dothidea hippophaeos CBS 18858 served as outgroup. Clades based on the ITS analysis of the isolates are labeled. The names of isolates collected in this study are bolded. The scale bar indicates 0.05 expected changes per site per branch. 


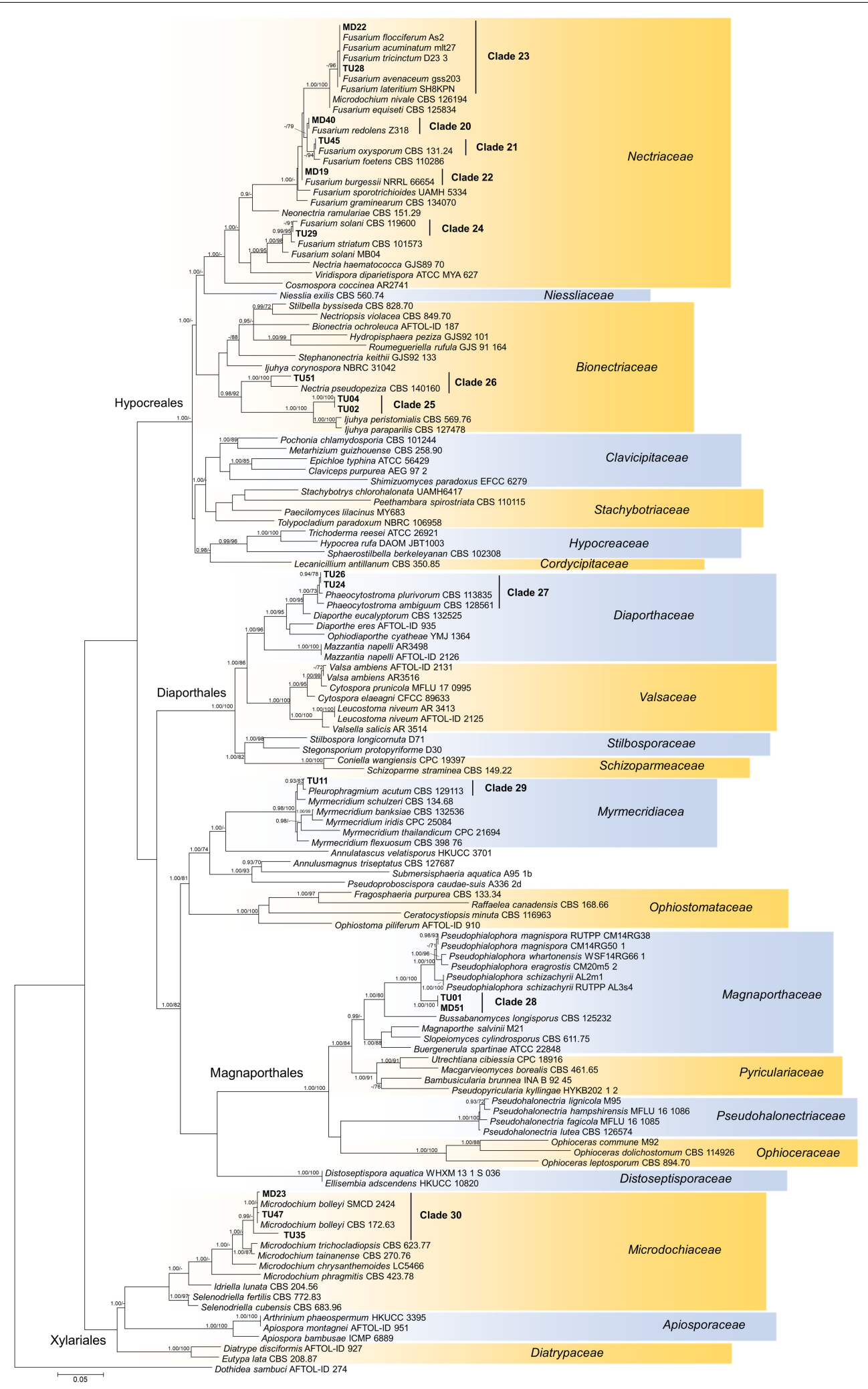

FIGURE 5 | Maximum likelihood (RAXML) phylogenetic tree of representative sequences from Sordariomycetes based on the analysis of three loci (LSU, ITS, and TEF). Bayesian posterior probabilities ( $\geq 90$ ) are shown before slashes; ML bootstrap support values $(\geq 70)$ are shown after slashes. Dothidea sambuci AFTOL ID 274 served as outgroup. Clades based on the ITS analysis of the isolates are labeled. Isolates collected in this study are bolded. The scale bar indicates 0.05 expected changes per site per branch. 
The isolate TU05 forms a clade with $D$. delta isolates, and two distinct isolates, TU37 and MD12, might represent novel species within Darksidea (Figure 6).

The multilocus phylogenetic analysis showed that, among related basidiomycetous sequences from GenBank, our isolates represented four lineages (Figure 7), which were already shown by the ITS phylogeny (Figure 2). Each lineage represented distinct lineages and potential new taxa within Agaricomycotina. Clades 32, 33, and 34 represented distant families in Agaricales, but their phylogenetic position is ambiguous. Clade 31, represented by three isolates, belonged to Hymenochaetaceae and formed a well-supported new lineage within Hymenochaete.

\section{DISCUSSION}

Dark septate endophytes are a widely distributed group of fungi, and, based on their dominance in belowground tissues of plants of grasslands worldwide (Jumpponen, 2001; Kovács and Szigetvári, 2002; Mandyam and Jumpponen, 2005; Herrera et al., 2010; Su et al., 2010; Fracchia et al., 2011; Knapp et al., 2012; Loro et al., 2012), these endophytes are hypothesized to be important functional members of fungal communities of harsh, nutrient-limited environments, such as arid and semiarid areas. The presence of the DSE hyphae and different structures in S. krylovii roots seems remarkable, similar to previous findings both in relatively close and distant grasslands. Hou et al. (2019), in their study, found extensive colonization in three plant species, including grasses investigated in semiarid continental sand lands of northern China. The abundant DSE colonization of gramineous plants has been reported from grassland ecosystems in various countries and continents (e.g., Kovács and Szigetvári, 2002; Mandyam and Jumpponen, 2008; Loro et al., 2012; Li et al., 2015; Xie et al., 2017).

Although knowledge of root endophytes of gramineous plants in Mongolian grasslands is poor, important findings have been published about the root-associated fungal communities in the so-called Inner Mongolian Steppe located in China (e.g., Su et al., 2010; Li et al., 2015; Xie et al., 2017). Su et al. (2010) investigated the endophytic fungi associated with $S$. grandis in the Inner Mongolia Steppe and, similar to our results, they found several lineages such as Darksidea species, Fusarium redolens, M. bolley, $P$. macrospinosa, and a basidiomycetous linage representing clade 34 in this study.

Because the isolates were collected from healthy, symptomless root sections, we consider here these fungi to be root endophytes according to the loose definition of endophytic fungi (see Wilson, 1995; Saikkonen et al., 1998). Based on the results of the in vitro tests we performed in this study with representative isolates and the non-host monocot leek, which was previously used for artificial tests for DSE fungi (Mandyam et al., 2010; Knapp et al., 2012), we found that representatives of most lineages showed, with few exceptions, no obvious negative effects on the leek. Six isolates caused visible symptoms and represented five clades belonging to novel basidiomycetous and Laburnicola lineages, and to the complex Fusarium and Aspergillus genera, none of which are typical or known DSEs. However, in many cases,

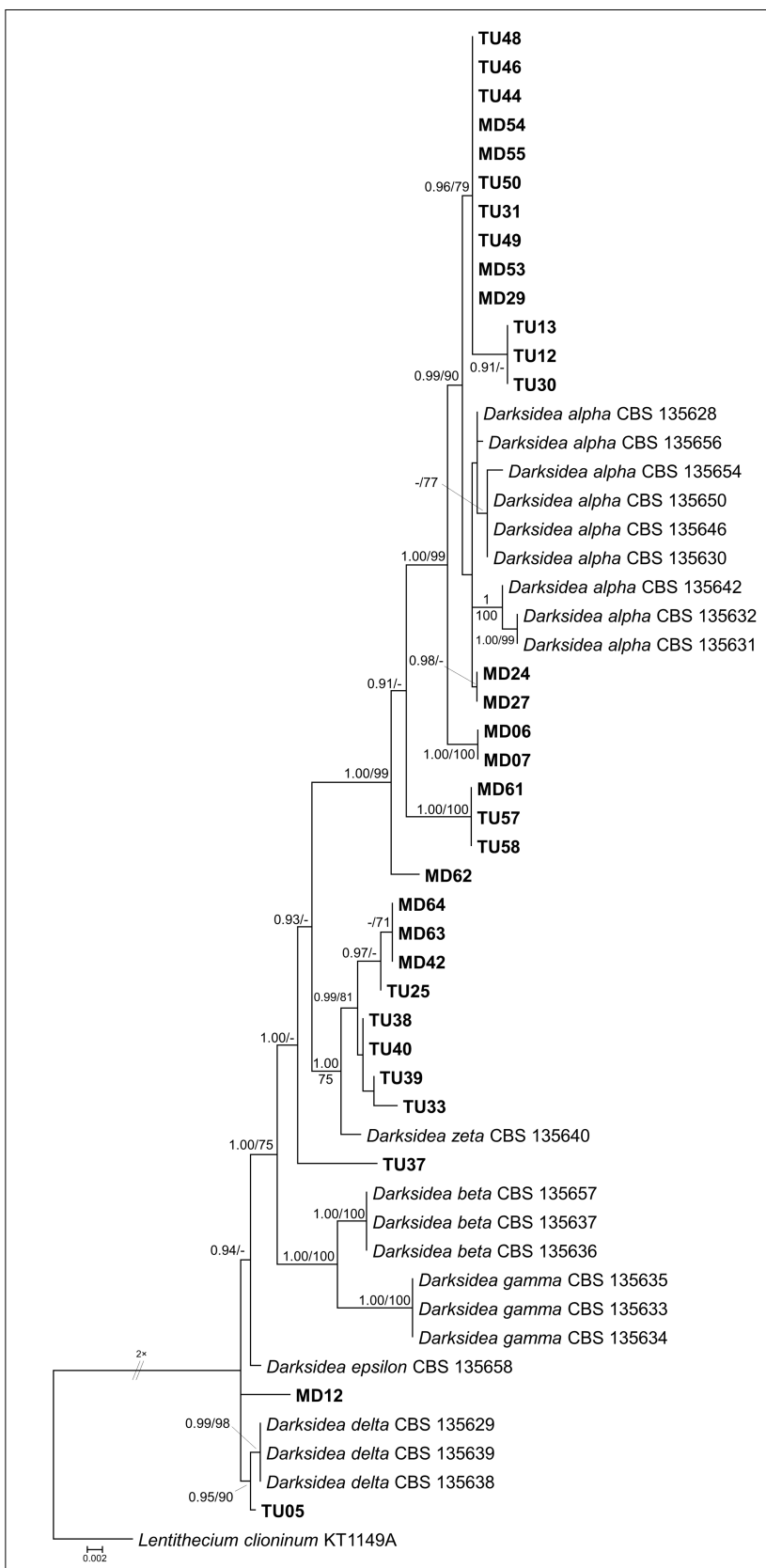

FIGURE 6 | Maximum likelihood (RAxML) phylogenetic tree of Darksidea isolates and representative sequences from Sordariomycetes based on the analysis of three loci (LSU, ITS, and TEF). Bayesian posterior probabilities $(\geq 90)$ are shown before slashes; ML bootstrap support values $(\geq 70)$ are shown after slashes. Lentithecium clioninum KT1149A served as outgroup. The names of isolates collected in this study are bolded. The scale bar indicates 0.002 expected changes per site per branch.

Fusarium species live within plant tissues without causing visible symptoms to the host, and can be important members of the endophytic community of the root and shoot (Knapp et al., 2012; Pereira et al., 2018). They can even be beneficial to the plant (Redman and Rodriguez, 2010). The negative effect of the isolate MD06, which represents a distinct Darksidea lineage 


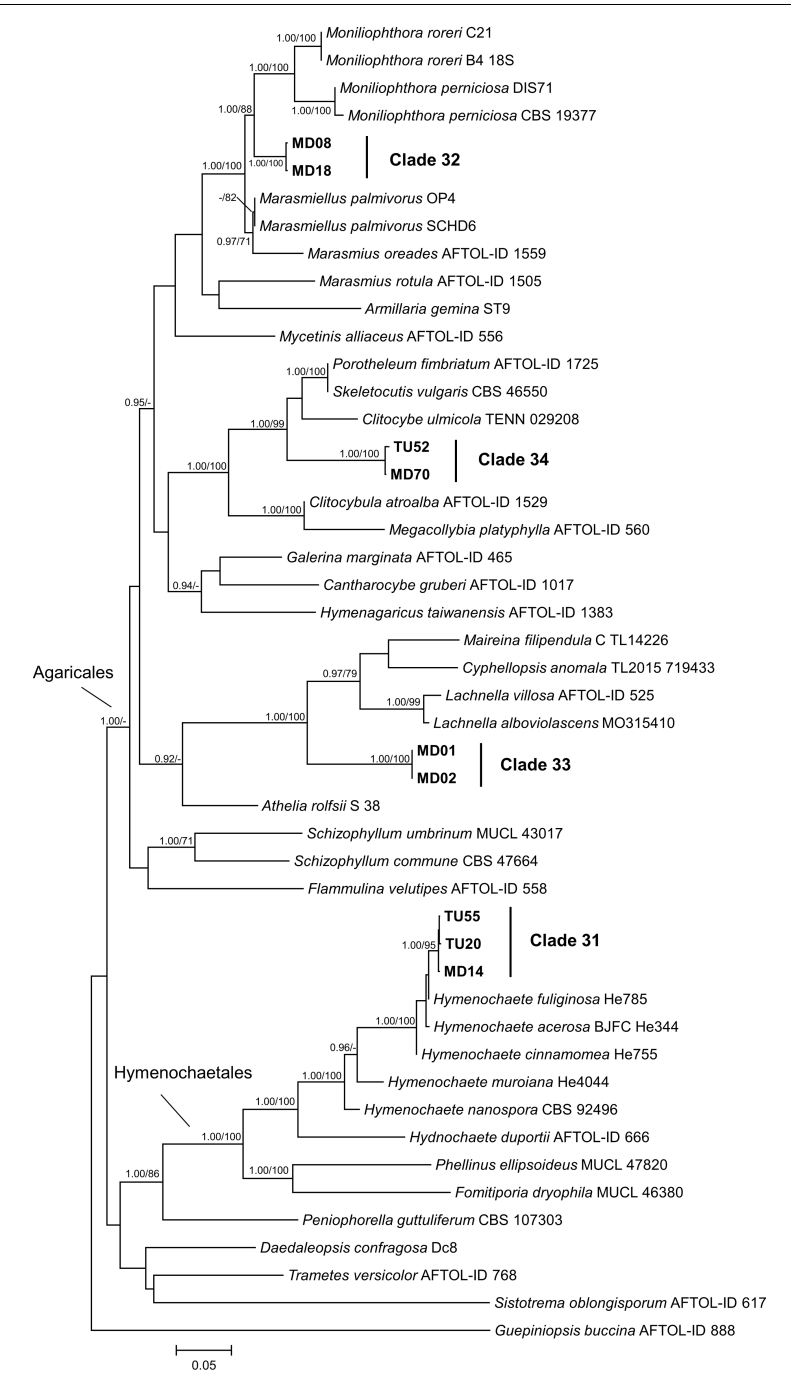

FIGURE 7 | Maximum likelihood (RAxML) phylogenetic tree of representative basidiomycetous isolates from Mongolia and representative sequences of the most similar BLAST matches from GenBank. The analysis was carried out based on four loci (LSU, ITS, SSU, and TEF). Bayesian posterior probabilities ( $\geq 90$ ) are shown before slashes; ML bootstrap support values $(\geq 70)$ are shown after slashes. Guepiniopsis buccina AFTOL ID 888 served as outgroup. Clades based on the ITS analysis of the isolates are labeled. Isolates collected in this study are bolded. The scale bar indicates 0.05 expected changes per site per branch.

together with MD07 was unexpected. This is the first note on negative effect in case of Darksidea isolates, which have never been considered as pathogen using several isolates in the same experimental setup (Knapp et al., 2012) and other in vitro systems (e.g., Li et al., 2018).

Only some fungal taxa were represented by most of the isolates; thus, these groups could be categorized as dominant or at least common members of the root endophytic community of the area. Ten clades were represented by only one isolate. However, isolation frequency does not necessarily mean the level of abundance in situ and could be the result of the bias of the isolation technique or the number of samples taken. In this study, we did not address quantitative questions and abundance of certain lineages; nevertheless, the dominance of some clades, such as the Darksidea species complex (clade 1) or Hymenochaete sp. (clade 31), was obvious.

One fourth of the isolates belongs to several lineages of the recently described and worldwide distributed diverse genus, Darksidea (Knapp et al., 2015), which consists mainly of grass or grassland associated fungi that dominate roots in prairies and steppes of Europe and North America (Porras-Alfaro et al., 2008; Knapp et al., 2012, 2015), and also occur in grasses of coastal sand dunes and marine cliffs (Sánchez-Márquez et al., 2008; Pereira et al., 2018). Species of Darksidea are common and dominant members of the DSE communities in grassland ecosystems, and have been reported from several countries (see Knapp et al., 2015). The genus was also found in the eastern region of the Steppe belt in roots of the grass $S$. grandis in the semiarid steppe zone of the Inner Mongolian Plateau (Su et al., 2010). Li et al. (2018) reported on Darksidea isolates collected from a superxerophytic shrub, Gymnocarpos przewalskii in Anxi Extra-Arid Desert National Nature Reserve and the Minqin Liangucheng National Nature Reserve, Gansu Province, northwest China. Hou et al. (2019) also isolated related fungi from roots of the clonal semishrub Hedysarum leave and the gramineous Psammochloa villosa in the $\mathrm{Mu}$ Us sandland, also in northwest China. This genus comprises six described species (Knapp et al., 2015); however, far more distinct lineages could be revealed within Darksidea based on the numerous related sequences deposited in public databases (e.g., Porras-Alfaro et al., 2008; Herrera et al., 2010; Glynou et al., 2016). Darksidea isolates are also diverse in colony morphology and highly vary, which is in contradiction with the similarity of their ITS or other DNA regions (Knapp et al., 2015). Here, we present further Darksidea isolates, representing several novel lineages within the genus, and within the most frequent and complex species D. alpha. Based on their presence in S. krylovii roots, Darksidea species might have a fundamental role in the life and annual growth cycle of the tussock. They might have a key role as a decomposer of dead roots owing to the generally expanded carbohydrate active enzymes of DSE fungi (Knapp et al., 2018). Based on our findings, we can support the conclusion of Knapp et al. (2015) that Darksidea is a common member of the core DSE community hypothesized to be shared by semiarid grassland areas worldwide.

Clade 3 represents another lineage of grass-associated DSEs, P. macrospinosa, a genomic analysis of which has been published recently by Knapp et al. (2018). This was the first comparative genomics of a DSE species of grasses. $P$. macrospinosa is distributed worldwide and common in grassdominated ecosystems of the North American prairies and European grasslands (Mandyam et al., 2010, 2012; Knapp et al., 2012; Mandyam and Jumpponen, 2014; Jumpponen et al., 2017) and might have an important role at these areas owing to its frequency. That species, among others, also was isolated by $\mathrm{Su}$ et al. (2010), from roots of another Stipa species, S. grandis, in Inner Mongolia. Jumpponen et al. (2017) during a field survey of rhizobiomes, comparing communities of different grassland sites across the prairies of the United States, found that after 
Gibberella/Fusarium species ( 23\%), Periconia was the second most abundant genus, comprising almost $15 \%$ of the isolates collected. This reinforced the belief that it is of major importance in these fields. In Periconiaceae, another lineage, the recently described F. fulophazii (clade 2) was found (Knapp et al., 2015), which is also a common grass endophyte in sandy grasslands of the Great Hungarian Plain; however, prior to this study, it was found only in Hungary.

A significant portion, more than one-fifth of the isolates, were basidiomycetes, representing four distinct lineages. This is quite notable compared with root-colonizing endophytes isolated from grasses in sites of the Eurasian steppe belt (e.g., Sánchez-Márquez et al., 2008; Su et al., 2010; Knapp et al., 2012), where the number of isolates belonging to any basidiomycetous taxa was negligible. This phenomenon may be the result of the diverse isolation techniques mentioned in the literature, in which the media used for isolation of the fungi growing from the root also differs.

Isolates of clades 5-7 grouped with Laburnicola species based on the analyses of ITS, LSU and SSU sequences, and seem to represent novel species within the genus, which consists mainly of saprobes on Laburnum debris (Wanasinghe et al., 2016).

Although clade 25 comprised fungi with 100\% ITS similarity with an isolate (MK808464) from a grassland in the North American Great Plains, their further closest matches (less than $92 \%$ similarity) were the Ijuhya species. This genus comprises the newly described I. vitellina (Ashrafi et al., 2017), which destructively parasitizes eggs inside cysts of the nematode Heterodera filipjevi, similarly to another recently introduced taxon, Polyphilus sieberi, that also behaves as common root endophyte but colonizing truffle ascomata, too (Ashrafi et al., 2018).

More than half $(60 \%)$ of the isolates collected from S. krylovii belong to Pleosporales, which is the largest order of Dothideomycetes (Zhang et al., 2012), and one of the most represented orders in root-associated communities of grassland ecosystems (Porras-Alfaro et al., 2008; Knapp et al., 2012; Jumpponen et al., 2017). It is worth noting the absence of the widely studied helotialean DSE, Phialocephala fortinii s.l-Acephala applanata species complex (PAC), the common and abundant group of endophytes in temperate and boreal coniferous forested ecosystems, as well as other species in Helotiales (Dean et al., 2013; Sieber and Grünig, 2013; Vohník et al., 2013). Instead of the helotialean dominance in forest ecosystems, the pleosporalean fungi seem to be the common dominant root endophytes in grassland ecosystems along the Holarctic regions (Porras-Alfaro et al., 2008; Mandyam et al., 2010; Knapp et al., 2012, 2015; Jumpponen et al., 2017).

\section{CONCLUSION}

In the present work, we investigated root-colonizing fungal endophytes of a common grass species of the steppes of Mongolia, which represent extended grasslands suffering from desertification and damage from anthropogenic activities (Liu et al., 2013). Here, we gained isolates from the roots of S. krylovii from the Mongolian grassland ecosystem, and carried out molecular identification of the isolated fungi. Although a majority of the isolates could be identified at the genus or species level, distinct lineages, probably representing novel taxa, are present among these endophytes. We have identified numerous fungi, which were detected in steppes not only from the Asian steppe ecosystems, but also from the prairies of North America and the sandy grasslands of Europe. Common and dominant lineages of grassland endophytes were also found in this study. Therefore, our results indicate the presence of common and dominant members of the DSE community of grasslands worldwide and strengthen our previous hypotheses on that core fungal community of those areas (Knapp et al., 2012).

\section{DATA AVAILABILITY STATEMENT}

All datasets generated for this study are included in the article/Supplementary Material.

\section{AUTHOR CONTRIBUTIONS}

DK and GK conceived the study. DK, EB, BO, and GK contributed to the sampling design and wrote the manuscript. All authors contributed to the data collection, critically reviewed and edited the manuscript, and approved its publication. DK, II, EB, SC, PB-N, and GA performed the experiments. DK, II, and GK performed the data interpretation.

\section{FUNDING}

This research was supported by the National Research, Development and Innovation Office, Hungary (NKFIH KH-109102 and KH-130401), the ELTE Institutional Excellence Program (1783-3/2018/FEKUTSRAT) of the Hungarian Ministry of Human Capacities, the János Bolyai Research Scholarship of the Hungarian Academy of Sciences to DK, and the Stipendium Hungaricum Programme.

\section{ACKNOWLEDGMENTS}

We thank Sascha Schulz, Anand Bayarsaikhan, and SukhErdene Bayarsaikhan for their crucial help in sampling. We also thank Bálint Dima (Eötvös Loránd University, Budapest) for his valuable comments and help in the laboratory works.

\section{SUPPLEMENTARY MATERIAL}

The Supplementary Material for this article can be found online at: https://www.frontiersin.org/articles/10.3389/fmicb.2019. 02565/full\#supplementary-material

TABLE S1 | GenBank accession numbers of the different sequences of different isolates gained in this study. 
TABLE S2 | GenBank accession numbers of sequences used for phylogenetic analyses.

\section{REFERENCES}

Altschul, S. F., Gish, W., Miller, W., Myers, E. W., and Lipman, D. J. (1990). Basic local alignment search tool. J. Mol. Biol. 215, 403-410. doi: 10.1016/S00222836(05)80360-2

Andrade-Linares, D. R., Grosch, R., Franken, P., Rexer, K. H., Kost, G., Restrepo, S., et al. (2011). Colonization of roots of cultivated Solanum lycopersicum by dark septate and other Ascomycetous endophytes. Mycologia 103, 710-721. doi: 10.3852/10-329

Ashrafi, S., Helaly, S., Schroers, H. J., Stadler, M., Richert-Poeggeler, K. R., Dababat, A. A., et al. (2017). Ijuhya vitellina sp. nov., a novel source for chaetoglobosin A, is a destructive parasite of the cereal cyst nematode Heterodera filipjevi. PLoS One 12:e0180032. doi: 10.1371/journal.pone.0180032

Ashrafi, S., Knapp, D. G., Blaudez, D., Chalot, M., Maciá-Vicente, J. G., Zagyva, I., et al. (2018). Inhabiting plant roots, nematodes, and truffles - polyphilus, a new helotialean genus with two globally distributed species. Mycologia 110, 286-299. doi: 10.1080/00275514.2018.1448167

Begzsuren, S., Ellis, J. E., Ojima, D. S., Coughenour, M. B., and Chuluun, T. (2004). Livestock responses to droughts and severe winter weather in the gobi three beauty National Park, Mongolia. J. Arid Environ. 59, 785-796. doi: 10.1016/j. jaridenv.2004.02.001

Bereneva, I. A. (1992). "Peculiarities of studies and methods of assessment of climatic resources of complex ecosystems of Mongolia," in Ecology and Nature Management in Mongolia (In Russian), ed. N. I. Dorofeyuk, (Moscow, FL: Gugk), 25-32.

Card, S. D., Faville, M. J., Simpson, W. R., Johnson, R. D., Voisey, C. R., de Bonth, A. C., et al. (2014). Mutualistic fungal endophytes in the triticeae-survey and description. FEMS Micr. Ecol. 88, 94-106. doi: 10.1111/1574-6941.12273

Chen, Y., Lee, G., Lee, P., and Oikawa, T. (2007). Model analysis of grazing effect on above-ground biomass and above-ground net primary production of a Mongolian grassland ecosystem. J. Hydr. 333, 155-164. doi: 10.1016/j.jhydrol. 2006.07.019

Dean, S. L., Farrer, E. C., Taylor, D. L., Porras-Alfaro, A., Suding, K. N., and Sinsabaugh, R. L. (2013). Nitrogen deposition alters plant-fungal relationships: linking belowground dynamics to aboveground vegetation change. Mol. Ecol. 23, 1364-1378. doi: 10.1111/mec.12541

Fernandez-Gimenez, M. E., and Allen-Diaz, B. (1999). Testing a non-equilibrium model of rangeland vegetation dynamics in Mongolia. J. Appl. Ecol. 36, 871-885. doi: 10.1046/j.1365-2664.1999.00447.x

Fracchia, S., Krapovickas, L., Aranda-Rickert, A., and Valentinuzzi, V. S. (2011). Dispersal of arbuscular mycorrhizal fungi and dark septate endophytes by ctenomys cf. knighti (Rodentia) in the northern monte desert of Argentina. J. Arid Environ. 75, 1016-1023. doi: 10.1016/j.jaridenv.2011.04.034

Gardes, M., and Bruns, T. D. (1993). ITS primers with enhanced specificity for basidiomycetes-application to the identification of mycorrhizae and rusts. Mol. Ecol. 2, 113-118. doi: 10.1111/j.1365-294x.1993.tb00005.x

Glynou, K., Ali, T., Buch, A. K., Haghi Kia, S., Ploch, S., Xia, X., et al. (2016). The local environment determines the assembly of root endophytic fungi at a continental scale. Env. Microbiol. 18, 2418-2434. doi: 10.1111/14622920

Herrera, J., Khidir, H. H., Eudy, D. M., Porras-Alfaro, A., Natvig, D. O., and Sinsabaugh, R. L. (2010). Shifting fungal endophyte communities colonize Bouteloua gracilis: effect of host tissue and geographical distribution. Mycologia 102, 1012-1026. doi: 10.3852/09-264

Hou, L., He, X., Li, X., Wang, S., and Zhao, L. (2019). Species composition and colonization of dark septate endophytes are affected by host plant species and soil depth in the Mu Us sandland, northwest China. Fungal Ecol. 39, 276-284. doi: 10.1016/j.funeco.2019.01.001

Jumpponen, A. (2001). Dark septate endophytes-are they mycorrhizal? Mycorrhiza 11, 207-211. doi: 10.1007/s005720100112

Jumpponen, A., Herrera, J., Porras-Alfaro, A., and Rudgers, J. (2017). "Biogeography of root-associated fungal endophytes," in Biogeography of Mycorrhizal Symbiosis, ed. L. Tedersoo, (Cham, FL: Springer), 195-222. doi: 10.1007/978-3-319-56363-3_10
TABLE S3 | Closest BLAST matches for ITS sequence of representative isolates of DSE clades.

Kang, L., Han, X., Zhang, Z., and Sun, O. J. (2007). Grassland ecosystems in China: review of current knowledge and research advancement. Philos. Trans. R. Soc. B Biol. Sci. 362, 997-1008. doi: 10.1098/rstb.2007.2029

Katoh, K., and Standley, D. M. (2013). MAFFT multiple sequence alignment software version 7: improvements in performance and usability. Mol. Biol. Evol. 30, 772-780. doi: 10.1093/molbev/mst010

Khidir, H. H., Eudy, D. M., Porras-Alfaro, A., Herrera, J., Natvig, D. O., and Sinsabaugh, R. L. (2010). A general suite of fungal endophytes dominate the roots of two dominant grasses in a semiarid grassland. J. Arid. Environ. 74, 35-42. doi: 10.1016/j.jaridenv.2009.07.014

Knapp, D. G., and Kovács, G. M. (2016). Interspecific metabolic diversity of rootcolonizing endophytic fungi revealed by enzyme activity tests. FEMS Microbiol. Ecol. 92:12. doi: 10.1093/femsec/fiw190

Knapp, D. G., Kovács, G. M., Zajta, E., Groenewald, J. Z., and Crous, P. W. (2015). Dark septate endophytic pleosporalean genera from semiarid areas. Persoonia 35:87. doi: 10.3767/003158515X687669

Knapp, D. G., Németh, J. B., Barry, K., Hainaut, M., Henrissat, B., Johnson, J., et al. (2018). Comparative genomics provides insights into the lifestyle and reveals functional heterogeneity of dark septate endophytic fungi. Sci. Rep. 8:6321. doi: 10.1038/s41598-018-24686-4

Knapp, D. G., Pintye, A., and Kovács, G. M. (2012). The dark side is not fastidiousdark septate endophytic fungi of native and invasive plants of semiarid sandy areas. PLoS One 7:e32570. doi: 10.1371/journal.pone.0032570

Kovács, G. M., Rudnóy, S., Vágvölgyi, C., Lásztity, D., Rácz, I., and Bratek, Z. (2001). Intraspecific invariability of the ITS region of rDNA of terfezia terfezioides in Europe. Folia Microbiol. 46, 423-426. doi: 10.1007/BF02814433

Kovács, G. M., and Szigetvári, C. (2002). Mycorrhizae and other root-associated fungal structures of the plants of a sandy grassland on the Great Hungarian Plain. Phyton 42, 211-223.

Li, B., He, X., He, C., Chen, Y., and Wang, X. (2015). Spatial dynamics of dark septate endophytes and soil factors in the rhizosphere of Ammopiptanthus mongolicus in Inner Mongolia. China Symbiosis 65, 75-84. doi: 10.1007/ s13199-015-0322-6

Li, X., He, X., Hou, L., Ren, Y., Wang, S., and Su, F. (2018). Dark septate endophytes isolated from a xerophyte plant promote the growth of Ammopiptanthus mongolicus under drought condition. Sci. Rep. 8:7896. doi: 10.1038/s41598018-26183-0

Li, Y., Liu, Y., Wang, Y., Niu, L., Xu, X., and Tian, Y. (2014). Interactive effects of soil temperature and moisture on soil $\mathrm{N}$ mineralization in a Stipa krylovii grassland in Inner Mongolia. China J. Arid Land 6, 571-580. doi: 10.1007/ s40333-014-0025-5

Liu, G., Xie, X., Ye, D., Ye, X., Tuvshintogtokh, I., Mandakh, B., et al. (2013). Plant functional diversity and species diversity in the Mongolian steppe. PLoS One 8:e77565. doi: 10.1371/journal.pone.0077565

Loro, M., Valero-Jiménez, C. A., Nozawa, S., and Márquez, L. M. (2012). Diversity and composition of fungal endophytes in semiarid Northwest Venezuela. J. Arid Environ. 85, 46-55. doi: 10.1016/j.jaridenv.2012.04.009

Mandyam, K., Fox, C., and Jumpponen, A. (2012). Septate endophyte colonization and host responses of grasses and forbs native to a tallgrass prairie. Mycorrhiza 22, 109-119. doi: 10.1007/s00572-011-0386-y

Mandyam, K., and Jumpponen, A. (2005). Seeking the elusive function of the root-colonising dark septate endophytic fungi. Stud. Mycol. 53, 173-189. doi: $10.3114 /$ sim.53.1.173

Mandyam, K., and Jumpponen, A. (2008). Seasonal and temporal dynamics of arbuscular mycorrhizal and dark septate endophytic fungi in a tallgrass prairie ecosystem are minimally affected by nitrogen enrichment. Mycorrhiza 18, 145-155. doi: 10.1007/s00572-008-0165-6

Mandyam, K., and Jumpponen, A. (2014). "Unraveling the dark septate endophyte functions: insights from the Arabidopsis model," in Advances in Endophytic Research, eds V. C. Verma, and A. C. Gange, (Berlin: Springer), 115-141. doi: 10.1007/978-81-322-1575-2_6

Mandyam, K., Loughin, T., and Jumpponen, A. (2010). Isolation and morphological and metabolic characterization of common endophytes in annually burned tallgrass prairie. Mycologia 102, 813-821. doi: 10.3852/09-212 
Mandyam, K. G., and Jumpponen, A. (2015). Mutualism-parasitism paradigm synthesized from results of root-endophyte models. Front. Microbiol. 5:776 doi: $10.3389 /$ fmicb. 2014.00776

Marx, D. H. (1969). The influence of ectotrophic mycorrhizal fungi on the resistance of pine roots to pathogenic infections. I. antagonism of mycorrhizal fungi to root pathogenic fungi and soil bacteria. Phytopathology 59, 153-163.

Mayerhofer, M. S., Kernaghan, G., and Harper, K. A. (2013). The effects of fungal root endophytes on plant growth: a meta-analysis. Mycorrhiza 23, 119-128. doi: 10.1007/s00572-012-0456-9

Murray, M. G., and Thompson, W. F. (1980). Rapid isolation of high molecular weight plant DNA. Nucleic Acids Res. 8, 4321-4326. doi: 10.1093/nar/8.19.4321

Newsham, K. K. (2011). A meta-analysis of plant responses to dark septate root endophytes. New Phytol. 190, 783-793. doi: 10.1111/j.1469-8137.2010.03611.x

Otgonsuren, B., and Lee, M. J. (2010). A native arbuscular mycorrhizal fungus, Acaulospora scrobiculata stimulated growth of mongolian crested wheatgrass (Agropyron cristatum (L.) Gaertn). Mong. J. Biol. Sci. 8, 33-41. doi: 10.22353/ mjbs.2010.08.12

Pereira, E., de Aldana, B. R. V., San Emeterio, L., and Zabalgogeazcoa, I. (2018). A survey of culturable fungal endophytes from Festuca rubra subsp. pruinosa, a grass from marine cliffs, reveals a core microbiome. Front. Microbiol. 9:3321. doi: 10.3389/fmicb.2018.03321

Porras-Alfaro, A., and Bayman, P. (2011). Hidden fungi, emergent properties: endophytes and microbiomes. Annu. Rev. Phytopathol. 49, 291-315. doi: 10. 1146/annurev-phyto-080508-081831

Porras-Alfaro, A., Herrera, J., Sinsabaugh, R. L., Odenbach, K. J., Lowrey, T., and Natvig, D. O. (2008). Novel root fungal consortium associated with a dominant desert grass. Appl. Environ. Microbiol. 74, 2805-2813. doi: 10.1128/AEM.0276907

Redman, R. S., and Rodriguez, R. J. (2010). Fungal Isolates and Their Use to Confer Salinity and Drought Tolerance in Plants. U. S Patent, US20100227357A1. doi: 10.1128/aem.02769-07

Rehner, S. A., and Buckley, E. (2005). A Beauveria phylogeny inferred from nuclear ITS and EF1- $\alpha$ sequences: evidence for cryptic diversification and links to cordyceps teleomorphs. Mycologia 97, 84-98. doi: 10.1080/15572536.2006. 11832842

Rehner, S. A., and Samuels, G. J. (1994). Taxonomy and phylogeny of Gliocladium analysed from nuclear large subunit ribosomal DNA sequences. Mycol. Res. 98, 625-634. doi: 10.1016/S0953-7562(09)80409-7

Retzer, V. (2007). Forage competition between livestock and Mongolian Pika (Ochotona pallasi) in Southern Mongolian mountain steppes. Basic Appl. Ecol. 8, 147-157. doi: 10.1016/j.baae.2006.05.002

Rodriguez, R., White, J., Arnold, A., and Redman, R. (2009). Fungal endophytes: diversity and functional roles. New Phytol. 182, 314-330. doi: 10.1111/j.14698137.2009.02773.x

Ronquist, F., and Huelsenbeck, J. P. (2003). MrBayes 3: bayesian phylogenetic inference under mixed models. Bioinformatics 19, 1572-1574. doi: 10.1093/ bioinformatics/btg180

Saikkonen, K., Faeth, S. H., Helander, M., and Sullivan, T. J. (1998). Fungal endophytes: a continuum of interactions with host plants. Annu. Rev. Ecol. Evol. Syst. 29, 319-343. doi: 10.1146/annurev.ecolsys.29.1.319

Sánchez-Márquez, S., Bills, G. F., and Zabalgogeazcoa, I. (2008). Diversity and structure of the fungal endophytic assemblages from two sympatric coastal grasses. Fungal Divers. 3, 1-17.

Sieber, T. N., and Grünig, C. R. (2013). "Fungal root endophytes," in Plant Roots: the Hidden Half, eds Y. Wasel, A. Eshel, and U. Kafkafi, (New York, FL: Marcel Dekker), 1-49.

Silvestro, D., and Michalak, I. (2012). raxmlGUI: a graphical front-end for RAxML. Org. Divers. Evol. 12, 335-337. doi: 10.1007/s13127-011-0056-0

Staden, R., Beal, K. F., and Bonfield, J. K. (2000). "The staden package, 1998," in Bioinformatics Methods and Protocols, eds S. Misener, and S. A. Krawetz, (Totowa, FL: Humana Press), 115-130. doi: 10.1385/1-59259-192-2:115

Stamatakis, A. (2014). RAxML version 8: a tool for phylogenetic analysis and post-analysis of large phylogenies. Bioinformatics 30, 1312-1313. doi: 10.1093/ bioinformatics/btu033

Su, Y. Y., Guo, L. D., and Hyde, K. D. (2010). Response of endophytic fungi of Stipa grandis to experimental plant function group removal in Inner Mongolia steppe. China. Fungal Divers. 43, 93-101. doi: 10.1007/s13225-010-0040-6

Tamura, K., Stecher, G., Peterson, D., Filipski, A., and Kumar, S. (2013). MEGA6: molecular evolutionary genetics analysis version 6.0. Mol. Biol. Evol. 30, 2725-2729. doi: 10.1093/molbev/mst197
Tuvshintogtokh, I. (2014). "Grassland in Mongolia and their degradation indicator plants," in Paper Presented at International Symposium on the East Asia Environmental Problems (EAEP2014), Fukuoka.

Ulziikhutag, N. (1989). Review of Flora of Mongolia. Ulaanbaatar: United Nations Development Programme.

Vandenkoornhuyse, P., Baldauf, S. L., Leyval, C., Straczek, J., and Young, J. P. W. (2002). Extensive fungal diversity in plant roots. Science 295, 2051-2051. doi: 10.1126/science.295.5562.2051

Vilgalys, R., and Hester, M. (1990). Rapid genetic identification and mapping of enzymatically amplified ribosomal DNA from several cryptococcus species. J. Bacteriol. 172, 4238-4246. doi: 10.1128/jb.172.8.4238-4246. 1990

Vohník, M., Mrnka, L., Lukešová, T., Bruzone, M. C., Kohout, P., and Fehrer, J. (2013). The cultivable endophytic community of Norway spruce ectomycorrhizas from microhabitats lacking ericaceous hosts is dominated by ericoid mycorrhizal Meliniomyces variabilis. Fungal Ecol. 6, 281-292. doi: 10. 1016/j.funeco.2013.03.006

Wanasinghe, D. N., Jones, E. B. G., Camporesi, E., Dissanayake, A. J., Kamolhan, S., Mortimer, P. E., et al. (2016). Taxonomy and phylogeny of Laburnicola gen. nov. and Paramassariosphaeria gen. nov (Didymosphaeriaceae, Massarineae, Pleosporales). Fungal Biol. 120, 1354-1373. doi: 10.1016/j.funbio.2016.06.006

Wang, J. L., Gao, Y. B., Zhao, N. X., Ren, A. Z., Ruan, W. B., Chen, L., et al. (2006). Morphological and RAPD analysis of the dominant species stipa krylovii roshev. in inner mongolia steppe. Bot. Stud. 47, 23-35.

White, T. J., Bruns, T., Lee, S., and Taylor, J. W. (1990). "Amplification and direct sequencing of fungal ribosomal RNA genes for phylogenetics," in PCR Protocols: A Guide to Methods and Applications, eds M. A. Innis, D. H. Gelfand, J. J. Sninsky, and T. J. White, (New York, FL: Academic Press Inc.), 315-322. doi: 10.1016/b978-0-12-372180-8.50042-1

Wilson, D. (1995). Endophyte: the evolution of a term, and clarification of its use and definition. Oikos 73, 274-276.

Xie, L., He, X., Wang, K., Hou, L., and Sun, Q. (2017). Spatial dynamics of dark septate endophytes in the roots and rhizospheres of Hedysarum scoparium in northwest China and the influence of edaphic variables. Fungal Ecol. 26, 135-143. doi: 10.1016/j.funeco.2017.01.007

Yakti, W., Andrade-Linares, D. R., Ngwene, B., Bitterlich, M., Kovács, G. M., and Franken, P. (2019a). "Phosphate nutrition in root-fungus interactions," in Endophytes for a Growing World, eds T. R. Hodkinson, F. M. Doohan, M. J. Saunders, and B. R. Murphy, (Cambridge FL: Cambridge University Press), 120-142. doi: 10.1017/9781108607667.007

Yakti, W., Kovács, G. M., Vági, P., and Franken, P. (2019b). Impact of dark septate endophytes on tomato growth and nutrient uptake. Plant Ecol. Divers. 11, 637-648. doi: 10.1080/17550874.2019.1610912

Yuan, Z. Y., Li, L. H., Han, X. G., Huang, J. H., Jiang, G. M., and Wan, S. Q. (2005). Soil characteristics and nitrogen resorption in Stipa krylovii native to northern China. Plant Soil 273, 257-268. doi: 10.1007/s11104-004-7941-7

Zhan, X., Li, L., and Cheng, W. (2007). Restoration of Stipa krylovii steppes in inner mongolia of China: assessment of seed banks and vegetation composition. J. Arid Environ. 68, 298-307. doi: 10.1016/j.jaridenv.2006.05.012

Zhang, Y., Crous, P. W., Schoch, C. L., and Hyde, K. D. (2012). Pleosporales. Fungal Divers. 53, 1-221. doi: 10.1007/s13225-011-0117-x

Zhao, H. L., Zhao, X. Y., Zhou, R. L., Zhang, T. H., and Drake, S. (2005). Desertification processes due to heavy grazing in sandy rangeland, inner Mongolia. J. Arid Environ. 62, 309-319. doi: 10.1016/j.jaridenv.2004.11.009

Zhao, N. X., Gao, Y. B., Wang, J. L., and Ren, A. Z. (2006). Genetic diversity and population differentiation of the dominant species Stipa krylovii in the inner mongolia steppe. Biochem. Genet. 44, 504-517. doi: 10.1007/s10528-0069054-x

Conflict of Interest: The authors declare that the research was conducted in the absence of any commercial or financial relationships that could be construed as a potential conflict of interest.

Copyright (c) 2019 Knapp, Imrefi, Boldpurev, Csíkos, Akhmetova, Berek-Nagy, Otgonsuren and Kovács. This is an open-access article distributed under the terms of the Creative Commons Attribution License (CC BY). The use, distribution or reproduction in other forums is permitted, provided the original author $(s)$ and the copyright owner(s) are credited and that the original publication in this journal is cited, in accordance with accepted academic practice. No use, distribution or reproduction is permitted which does not comply with these terms. 